\title{
The effects of Nigella sativa on thyroid function, serum Vascular Endothelial Growth Factor (VEGF) - 1, Nesfatin-1 and anthropometric features in patients with Hashimoto's thyroiditis: a randomized controlled trial
}

\author{
Mahdieh Abbasalizad Farhangi ${ }^{1 *}$, Parvin Dehghan ${ }^{1}$, Siroos Tajmiri $^{2}$ and Mehran Mesgari Abbasi ${ }^{3}$
}

\begin{abstract}
Background: Hashimoto's thyroiditis is an autoimmune disorder and the most common cause of hypothyroidism. The use of Nigella sativa, a potent herbal medicine, continues to increase worldwide as an alternative treatment of several chronic diseases including hyperlipidemia, hypertension and type 2 diabetes mellitus (T2DM). The aim of the current study was to evaluate the effects of Nigella sativa on thyroid function, serum Vascular Endothelial Growth Factor (VEGF) - 1, Nesfatin-1 and anthropometric features in patients with Hashimoto's thyroiditis.

Methods: Forty patients with Hashimoto's thyroiditis, aged between 22 and 50 years old, participated in the trial and were randomly allocated into two groups of intervention and control receiving powdered Nigella sativa or placebo daily for 8 weeks. Changes in anthropometric variables, dietary intakes, thyroid status, serum VEGF and Nesfatin-1 concentrations after 8 weeks were measured.

Results: Treatment with Nigella sativa significantly reduced body weight and body mass index (BMI). Serum concentrations of thyroid stimulating hormone (TSH) and anti-thyroid peroxidase (anti-TPO) antibodies decreased while serum T3 concentrations increased in Nigella sativa-treated group after 8 weeks. There was a significant reduction in serum VEGF concentrations in intervention group. None of these changes had been observed in placebo treated group. In stepwise multiple regression model, changes in waist to hip ratio (WHR) and thyroid hormones were significant predictors of changes in serum VEGF and Nesgfatin-1 values in Nigella sativa treated group $(P<0.05)$.

Conclusions: Our data showed a potent beneficial effect of powdered Nigella sativa in improving thyroid status and anthropometric variables in patients with Hashimoto's thyroiditis. Moreover, Nigella sativa significantly reduced serum VEGF concentrations in these patients. Considering observed health- promoting effect of this medicinal plant in ameliorating the disease severity, it can be regarded as a useful therapeutic approach in management of Hashimoto's thyroiditis.
\end{abstract}

Trial registration: Iranian registry of clinical trials (registration number IRCT2015021719082N4- Registered March-15-2015).

Keywords: Hashimoto's thyroiditis, Nigella sativa, VEGF, Nesfatin-1

\footnotetext{
* Correspondence: abbasalizad_m@yahoo.com

${ }^{1}$ Nutrition Research Center, Department of Community Nutrition, School of

Nutrition, Tabriz University of Medical Sciences, Tabriz, Iran

Full list of author information is available at the end of the article
} 


\section{Background}

Hashimoto's thyroiditis (HT) is an organ-specific T-cell mediated disease that affects the thyroid glands and is one of the most common human autoimmune disorders [1]. The disease affects $2 \%$ of general population and is ten times more prevalent in women than in men $[2,3]$. A significant proportion of patients have asymptomatic chronic autoimmune thyroiditis and $8 \%$ of woman $(10 \%$ of woman over 55 years of age) and $3 \%$ of men have subclinical hypothyroidism [4].

Hashimoto's thyroiditis is characterized by the presence of thyroid auto-antibodies such as anti-thyroid peroxidase (TPO-Ab) and anti-thyroglobulin (TG-Ab) antibodies in the serum while these antibodies have potential ability to deteriorate thyroid cells $[5,6]$. The disease is characterized by gradual thyroid failure and occasional goiter development and the untreated forms of Hashimoto's thyroiditis can ever lead to papillary thyroid cancer and thyroid carcinoma $[7,8]$.

From pathological point of view, thyroid enlargement and hyper-function in Hashimoto's thyroiditis is accompanied by a markedly increased blood flow and increased vascularization [9]. A number of growth and vasoactive factors are produced in thyroid and are considered to be potentially responsible for changes in thyroid microvasculature and blood flow; vascular endothelial growth factors (VEGF) is a hemodynamic glycoprotein with potent angiogenic and vascular permeability enhancing activities [10]. It has been proposed that VEGF and its receptors are present in epithelial cells of the thyroid and contribute in regulation of development and function of thyroid epithelial cells [10]. In fact VEGF is unique among angiogenic factors because it is both vascular endothelial cell-specific mitogen and is secreted by thyroid cancer cells and high thyroid stimulating hormone (TSH) concentrations in Hashimoto's thyroiditis promotes VEGF secretion from thyroid cancer cell lines [11].

Nesfatin-1, a peptide secreting from peripheral tissues, central and peripheral nervous system, is involved in the regulation of energy homeostasis related with food consumption mostly by passing through the blood-brain barrier [12]. Moreover, several recent studies have proposed the possible role of Nesfatin-1 in in thyroid dysfunction $[13,14]$. Liu et al. [15] reported that plasma Nesfain-1 levels are independently correlated with serum TSH concentrations in patients with T2DM. The Nesfatin-1 immuno-positive neurons have been reported to be colocalized with thyrotropin releasing hormone (TRH) neurons in the paraventricular nucleous (PVN) and the central Nesfatin-1 affects the membrane potential of TRH neurons suggesting the possible role of Nesfatin-1 in regulation of thyroid hormone function $[16,17]$.

Levothyroxine sodium is the treatment of choice for Hashimoto's thyroiditis; however its chronic use is related with cardiac dysfunction, left ventricular hypertrophy $[18,19]$ and rapid bone loss [20]. Nigella sativa is one of the medicinal plants and belongs to the Ranunculaceae family [21]. The seeds of the Nigella sativa are the main source of its active ingredients with considerable health promoting effects including antioxidant, anti-inflammatory and immune-modulatory properties and no side effects $[21,22]$. Numerous researches have extensively studied therapeutic actions of Nigella sativa in improving chronic disease status including diabetes, hyperlipidemia, hypertension and gastritis especially in animal models; while human studies in this filed are scarce and limiting [23, 24]. Moreover the health effects of Nigella sativa in Hashimoto's thyroiditis has been studied in only one animal model indicating its protective role in reversing hypothyroid status and ameliorating oxidative stress and thyroid cell damage in propylthiouracil (PTU)-induced hypothyroidism in rats [25]. In the current randomized clinical trial we aimed to evaluate the potential therapeutic effects of Nigella sativa powder on thyroid function and serum VEGF and Nesfatin-1 concentrations in patients with Hashimoto thyroiditis.

\section{Methods \\ Patients}

In the current double-blinded placebo-controlled trial, 40 patients with Hashimoto's thyroiditis were enrolled (Fig. 1). Subjects were recruited from outpatient endocrinology and metabolism clinics of Isfahan University of Medical Sciences. Inclusion criteria were as follows: age between 20 and 50 years and having Hashimoto's thyroiditis according to physician diagnosis. Exclusion criteria were as follows: taking any nutritional supplements for at least 3 months prior participation or during the trial, any history of autoimmune disease, cardiovascular events, other thyroid abnormalities including Grave's disease, being pregnant or lactating, any history of thyroid surgeries and being on any dietary regimens during and 3 months before recruitment in the trial. Participants were treated with levothyroxine while the drug dosage was stable from 6 weeks prior participation in the study to the end of the trial. The average full replacement dose of levothyroxine sodium was approximately $1.7 \mathrm{mcg} / \mathrm{kg} /$ day (e.g., 100-125 mcg/day for a $70 \mathrm{~kg}$ adult).

\section{Study design}

From 100 recruited subjects, 53 participants were excluded because of not meeting the inclusion criteria or decline to participate. Among remaining 47 patients, random permuted block procedure was performed and participants were randomly allocated into Nigella sativatreated $(n=23)$ or placebo-treated $(n=24)$ groups. During the trial, three patients in Nigella sativa-treated group were excluded from the study because of itching 


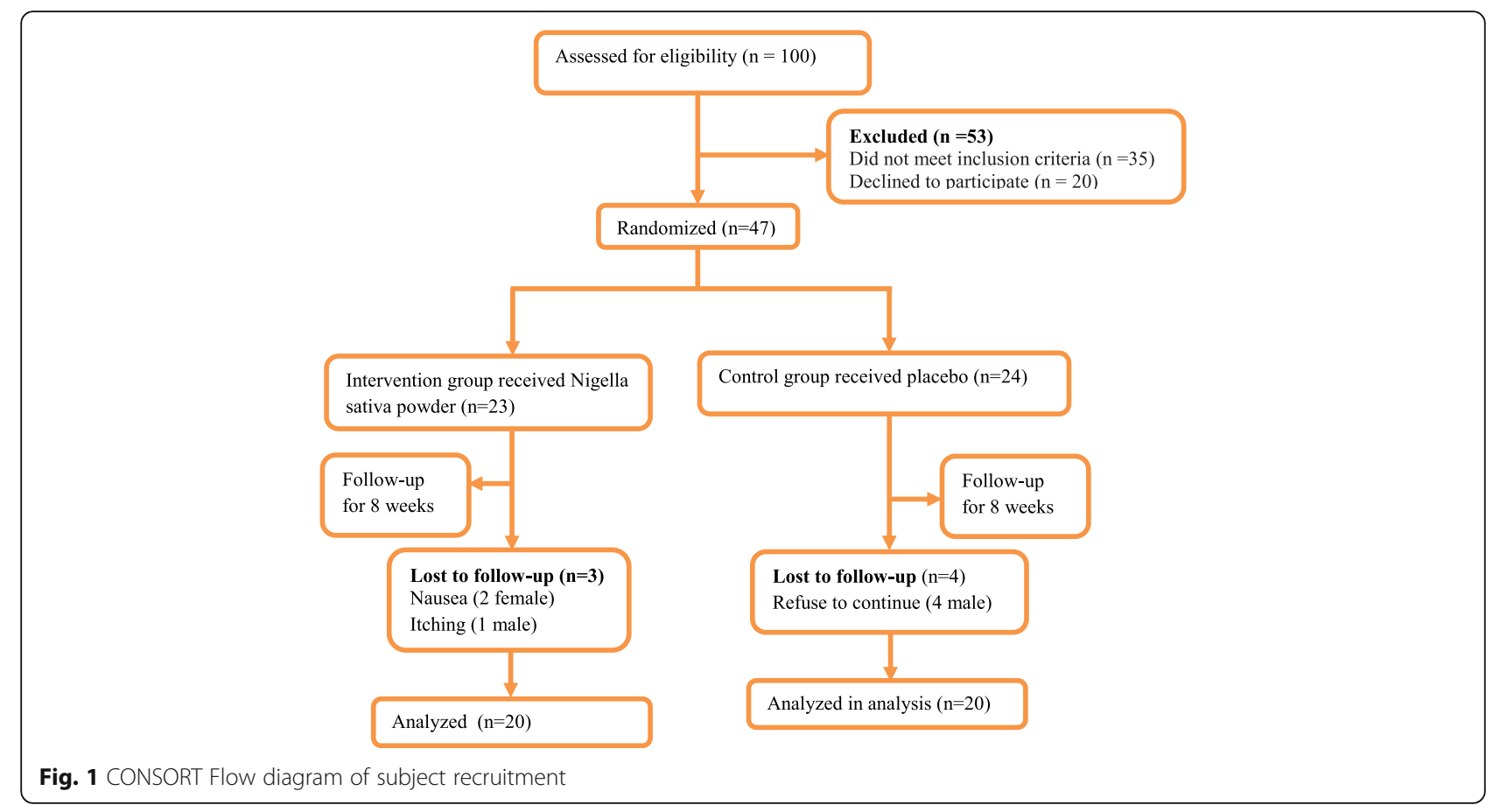

and nausea; while four patients in control group refused to continue the trial. Therefore, totally 20 patients in each group completed the study. Patients in the intervention group received a daily dose of $2 \mathrm{~g}$ Nigella sativa powder per day and placebo group received $2 \mathrm{~g}$ starches per day for 8 weeks. The dose of the Nigella sativa and time period of the study had been selected according to review of the previous studies indicating the effectiveness of $2 \mathrm{~g}$ of Nigella sativa or even lesser doses and 8 weeks study duration in treatment of numerous metabolic disorders including immune disturbances and lipid abnormalities [26, 27].

Black seed powders were obtained from corns grown in Isfahan bought by a local market (Sad-Giah market, Isfahan, Iran) and were prepared by the Goldaroo pharmaceutical company (Goldaro Pharmaceutical Co. Isfahan, Iran). The black seeds were milled in a grinder and a purified powder was prepared. The seeds were identified and authenticated by Dr. Mahdieh Abbasalizad Farhangi, supervisor of the project from Department of Nutrition, Tabriz University of Medical Sciences, Tabriz, Iran. Thereafter, Nigella sativa seeds were processed into pharmaceutical grade capsules containing Nigella sativa powder and bottled according to Good Manufacturing Practices (GMP). Each capsule was prepared containing $1 \mathrm{~g}$ powder of Nigella Sativa, and each bottle contained 112 capsules, for 8 weeks period of the study. While for the placebo, we used starch bought from the same market and the entire processes of its capsulation was similar to Nigella sativa seeds preparation. Participants in intervention and placebo groups received two capsules daily, taking it immediately before lunch and dinner respectively.

Randomization procedure was performed by a third investigator who had no clinical involvement in the trial to ensure complete blinding in the randomization process. Randomization was done according to computer- generated numbers and was kept in consecutively numbered envelopes opened at the moment of participant enrollment into the study. A follow-up procedure was done with weekly telephone contacts to ensure that subjects consumed the supplements regularly.

\section{Anthropometric and nutritional assessments}

Body weight and height were measured with a calibrated digital scale and stadimeter respectively. BMI was calculated as weight $(\mathrm{kg})$ divided by height $(\mathrm{cm})$ squared. Waist circumference (WC) was measured in horizontal plane, midway between the lowest rib and the iliac crest with a measuring tape in centimeter. Waist to hip ratio (WHR) was calculated by WC divided by hip circumference (HC). The dietary assessments were performed using a 3-day food record, covering two weekdays and one weekend day, to estimate total energy, carbohydrate, protein, fat and antioxidant vitamins consumption. Because of the antioxidant nature of Nigella sativa the intake of vitamin $\mathrm{E}$ and $C$ were specifically evaluated to ensure that no change in their consumption has been occurred throughout the trial and to rule out their possible confounding effect on study parameters. Nutrient analysis of the 3-day food record was performed using the Nutritionist IV software (N-squared Computing, Salem, OR, USA). 


\section{Biochemical assays}

Fasting blood samples were obtained from all of the participants at the beginning and end of the trial. The serum and plasma samples were separated by centrifugation at $2500 \mathrm{rpm}$ for $10 \mathrm{~min}$ (Beckman Avanti J-25; Beckman Coulter, Brea, CA, USA) at room temperature. The serum samples were stored at $-70{ }^{\circ} \mathrm{C}$ immediately after centrifugation until their assays. Serum thyroidstimulating hormone (TSH), total triiodothyronine (T3) and total thyroxine (T4) were analyzed by enzyme linked immunosorbent assay (ELISA Kit, Pishtaz Tebe Co., Tehran, Iran) according to the manufacturer's instructions. Anti-thyroid peroxidase antibody was measured by the commercially solid-phase ELISA kit (Aeskulisa, Wendelsheim, Germany). Serum concentration of VEGF and Nesfatin-1 were measured by commercial ELISA kits (Hangzhou East biopharm Co, USA). The sensitivity of these assays was $10.42 \mathrm{ng} / \mathrm{l}$ and $0.15 \mathrm{ng} / \mathrm{ml}$ respectively.

\section{Statistical assays}

Statistical analysis was performed by SPSS $^{\mathrm{m}}$ statistical software (SPSS Inc., Chicago, IL, USA). Quantitative data were presented as mean \pm standard deviation (SD), and qualitative data were demonstrated as frequency and percent. One-sample Kolmogorov-Smirnov test was used to assess the normality of data. Between groups comparisons of continuous variables were performed by independent sample $t$-test. Paired $t$-test was used for before and after intervention comparisons. Analysis of covariance (ANCOVA) was used to identify any differences between two treatment groups after intervention adjusting for the confounding effects of baseline concentrations of parameter, age and gender. Stepwise multivariate linear regression model was used to evaluate the predictors of changes in VEGF and Nesfatin-1 concentrations. P-values less than 0.05 were considered to be significant. Sample size calculation was performed based on $80 \%$ power and an $\alpha$-error of $5 \%$ to detect treatment effect of Nigella sativa on serum TSH. Totally, 14 individuals were calculated. Allowing for $30 \%$ drop-out over 8 weeks of intervention, the total sample size required for the study was 40 individuals.

\section{Results}

The flowchart of the study is given in Fig. 1. A total of 40 patients completed the study. Three patients in Nigella sativa-treated group were excluded from the study because of itching and nausea; while four patients in control group refused to continue the trial. No other side effects were observed in the current study.

At baseline, there was no significant difference in general characteristics among groups. Nigella sativa supplementation significantly reduced anthropometric variables including weight, $\mathrm{BMI}, \mathrm{WC}$ and $\mathrm{HC}$ in patients with Hashimoto's thyroiditis $(P<0.05)$; while no significant change in placebo-treated group has been occurred (Table 1). Dietary energy and nutrient intakes before and after intervention are presented in Table 2. Energy and nutrient intakes were similar between groups before intervention and no significant change was observed after intervention. Serum TSH and anti-TPO concentrations reduced while serum T3 increased in Nigella sativa treated group $(P<0.05)$. Moreover, serum VEGF reduced significantly after 8 weeks of Nigella sativa supplementation $(P=0.02$, Table 3). In stepwise multiple linear regression analysis when change in serum VEGF concentrations was entered as dependent variable and change in anthropometric variables and thyroid hormones as independent variables (Table 4) one model was obtained indicating change in WHR as predictor of change in VEGF concentrations. In similar procedure when change in serum Nesfatin-1 was entered as dependent variable, change in WHR, TSH and T3 were its predictors $(P<0.05)$.

Table 1 General characteristics and anthropometric variables in treatment groups before and after intervention

\begin{tabular}{|c|c|c|c|}
\hline \multirow[t]{2}{*}{ N } & \multirow{2}{*}{$\begin{array}{l}\text { Nigella sativa } \\
N=20\end{array}$} & \multirow{2}{*}{$\begin{array}{l}\text { Placebo } \\
N=20\end{array}$} & \multirow[t]{2}{*}{$P+$} \\
\hline & & & \\
\hline Age (years) & $35.70 \pm 8.18$ & $33.95 \pm 8.72$ & 0.52 \\
\hline Levothyroxine $(\mathrm{mcg} / \mathrm{d})$ & $119.85 \pm 24.12$ & $118.46 \pm 22.12$ & 0.91 \\
\hline Female [n (\%)] & $17(85)$ & $17(85)$ & 0.89 \\
\hline \multicolumn{4}{|l|}{ Weight (kg) } \\
\hline Before & $70.52 \pm 12.27$ & $69.63 \pm 11.75$ & 0.81 \\
\hline After & 69.3911 .84 & 69.6211 .80 & 0.95 \\
\hline$P \neq$ & 0.004 & 0.91 & \\
\hline \multicolumn{4}{|l|}{ BMI (kg/m2) } \\
\hline Before & $27.10 \pm 4.63$ & $25.93 \pm 4.07$ & 0.40 \\
\hline After & 26.634 .42 & 25.954 .11 & 0.61 \\
\hline$P \neq$ & 0.002 & 0.65 & \\
\hline \multicolumn{4}{|l|}{ Waist Circumference (cm) } \\
\hline Before & $88.56 \pm 7.29$ & $88.69 \pm 7.41$ & 0.95 \\
\hline After & $87.72 \pm 6.92$ & $88.57 \pm 7.35$ & 0.71 \\
\hline$P \neq$ & 0.006 & 0.17 & \\
\hline \multicolumn{4}{|l|}{$\mathrm{HC}(\mathrm{cm})$} \\
\hline Before & $102.85 \pm 6.25$ & $101.77 \pm 6.84$ & 0.61 \\
\hline After & $101.56 \pm 5.51$ & $101.56 \pm 7.02$ & 0.99 \\
\hline$P \neq$ & 0.001 & 0.08 & \\
\hline \multicolumn{4}{|l|}{ WHR } \\
\hline Before & $0.86 \pm 0.052$ & $0.87 \pm 0.053$ & 0.53 \\
\hline After & $0.86 \pm 0.05$ & $0.87 \pm 4.11$ & 0.61 \\
\hline$P \neq$ & 0.38 & 0.53 & \\
\hline
\end{tabular}

$B M I$ body mass index, $W C$ waist circumference, $H C$ hip circumference, $W H R$ waist to hip ratio, $+P$ values for ANOCOVA after adjustment for age, gender, duration of the disease and variable's baseline value; $¥ P$ values for paired $t$-test. Data are presented as mean \pm SD or number (percent), the bolded $P$ values are statistically significant 
Table 2 Dietary intakes of energy and nutrients in treatment groups before and after intervention

\begin{tabular}{llll}
\hline$N$ & Nigella sativa & Placebo & $P \dagger$ \\
$N=20$ & $N=20$ & \\
\hline
\end{tabular}

Total calories (kcal/d)

$\begin{array}{llll}\text { Before } & 2251.90 \pm 349.58 & 2208.95 \pm 327.80 & 0.69 \\ \text { After } & 2236.40 \pm 248.27 & 2265.45 \pm 270.73 & 0.72 \\ P \neq & 0.77 & 0.32 & \end{array}$

Carbohydrate (\%)

$\begin{array}{lll}\text { Before } & 57.11 \pm 2.90 & 57.07 \pm 3.78 \\ \text { After } & 57.24 \pm 2.71 & 57.58 \pm 3.32 \\ P \neq & 0.26 & 0.67\end{array}$

Protein (\%)

$\begin{array}{lll}\text { Before } & 15.73 \pm 1.68 & 15.07 \pm 1.29 \\ \text { After } & 15.77 \pm 1.36 & 15.10 \pm 1.81 \\ P \neq & 0.94 & 0.94\end{array}$

Fat (\%)

$\begin{array}{lll}\text { Before } & 27.34 \pm 2.15 & 26.57 \pm 2.32 \\ \text { After } & 26.56 \pm 1.96 & 26.13 \pm 2.48 \\ P \neq & 0.51 & 0.51\end{array}$

Vitamin $\mathrm{E}(\mathrm{mg} / \mathrm{d})$

$\begin{array}{lll}\text { Before } & 2.98 \pm 1.08 & 3.43 \pm 1.48 \\ \text { After } & 2.89 \pm 1.64 & 3.40 \pm 1.19 \\ P \neq & 0.80 & 0.96\end{array}$

Vitamin C (mg/d)

\begin{tabular}{llll} 
Before & $79.75 \pm 22.69$ & $75.67 \pm 17.24$ & 0.52 \\
After & $28.37 \pm 11.84$ & $75.45 \pm 15.36$ & 0.59 \\
$P \neq$ & 0.77 & 0.91 & \\
\hline
\end{tabular}

Data are presented as mean $\pm \mathrm{SD},+P$ values for ANOCOVA after adjustment for age, gender, duration of the disease and variable's baseline value; $¥ P$ values for paired t-test

\section{Discussion}

In the current study we showed a meaningful impact of 8 weeks treatment with Nigella sativa on thyroid function, anthropometric features and serum VEGF concentrations in patients with Hashimoto's thyroiditis. However changes in serum Nesfatin-1 concentrations were not significant. These findings were in accordance of findings of two animal studies; in one study by Khalawi AA [25] Nigella sativa oil improved hypothyroid status and decreased serum TSH concentrations in rats; in other animal study by Al-Asoom et al. [28] daily oral administration of $800 \mathrm{mg} / \mathrm{kg}$ Nigella sativa in male Wistar rats reduced serum thyroxine concentrations. However in our study, for the first time, we clearly demonstrated its beneficial role on improving thyroid function in human.

The seeds of Nigella sativa known as black seeds or black cumin have long been used in folk medicine in the middle and Far East as a traditional medicine for a wide
Table 3 Metabolic parameters in treatment groups before and after intervention

\begin{tabular}{|c|c|c|c|}
\hline \multirow[t]{2}{*}{ N } & Nigella sativa & Placebo & \multirow[t]{2}{*}{$P+$} \\
\hline & $N=20$ & $N=20$ & \\
\hline \multicolumn{4}{|c|}{ TSH (mIU/l) } \\
\hline Before & $6.42 \pm 3.86$ & $8.14 \pm 7.28$ & 0.35 \\
\hline After & $4.13 \pm 2.35$ & $8.27 \pm 7.21$ & 0.02 \\
\hline$P \neq$ & 0.03 & 0.40 & \\
\hline \multicolumn{4}{|c|}{ T3 (mmol/l) } \\
\hline Before & $0.92 \pm 0.27$ & $1.18 \pm 0.36$ & 0.017 \\
\hline After & $1.06 \pm 0.34$ & $1.16 \pm 0.35$ & 0.39 \\
\hline$P \neq$ & 0.008 & 0.15 & \\
\hline \multicolumn{4}{|c|}{ T4 (mmol/l) } \\
\hline Before & $8.07 \pm 2.56$ & $7.97 \pm 3.11$ & 0.91 \\
\hline After & $8.89 \pm 1.43$ & $7.63 \pm 2.23$ & 0.04 \\
\hline$P \neq$ & 0.21 & 0.32 & \\
\hline \multicolumn{4}{|c|}{ Anti-TPO (IU/ml) } \\
\hline Before & $294.55 \pm 210.05$ & $278.10 \pm 170.77$ & 0.78 \\
\hline After & $147.99 \pm 158.33$ & $274.30 \pm 167.20$ & 0.01 \\
\hline$P \neq$ & 0.019 & 0.28 & \\
\hline \multicolumn{4}{|c|}{ Nesfatin-1 (ng/ml) } \\
\hline Before & $41.80 \pm 28.33$ & $25.86 \pm 20.91$ & 0.049 \\
\hline After & $37.63 \pm 5.91$ & $26.75 \pm 23.95$ & \\
\hline$P \neq$ & 0.34 & 0.69 & \\
\hline \multicolumn{4}{|c|}{ VEGF (ng/L) } \\
\hline Before & $3521.13 \pm 395.95$ & $2101.73 \pm 339.29$ & 0.17 \\
\hline After & $2100.17 \pm 36,082$ & $2100.17 \pm 360.82$ & 0.25 \\
\hline$P \neq$ & 0.02 & 0.99 & \\
\hline
\end{tabular}

Data are presented as mean \pm SD. $+P$ values for ANOCOVA after adjustment for age, gender and baseline concentration of parameter; $¥ P$ values for paired $t$-test. TSH, thyroid-stimulating hormone; $T 3$ triiodothyronine, $T 4$ thyroxine, VEGF vascular endothelial growth factor, the bolded $P$ values are statistically significant

Table 4 Stepwise multivariate linear regression analysis in Nigellasativa treated group with changes in VEGF and Nesfatin-1 as dependent variables and changes in anthropometric variables and thyroid hormones as dependent variables

\begin{tabular}{|c|c|c|c|c|c|}
\hline & B & SE & $\beta$ & $\mathrm{t}$ & P \\
\hline \multicolumn{6}{|c|}{$\Delta$ Nesfatin (as dependent variable) } \\
\hline$\Delta \mathrm{WHR}$ & 387.54 & 183.92 & 0.24 & 2.10 & 0.05 \\
\hline$\Delta \mathrm{TSH}$ & 1.34 & 0.63 & 0.30 & 2.11 & 0.05 \\
\hline$\Delta \mathrm{T} 3$ & -59.11 & 14.49 & -0.63 & -4.07 & 0.001 \\
\hline
\end{tabular}

$\Delta$ VEGF (as dependent variable)

$\begin{array}{llllll}\Delta W H R & 35449.84 & 18234.88 & 0.31 & 1.94 & \mathbf{0 . 0 5}\end{array}$

WHR waist to hip ratio, TSH thyroid-stimulating hormone, T3 triiodothyronine, T4 thyroxine, VEGF vascular endothelial growth factor, $B$ unstandardized coefficient, $S E$ standard error, $\beta$ standardized coefficient, $t$ the student's $t$ distribution, $P$ level of significance 
range of disease including infections, obesity, hypertension and gastrointestinal problems [21]. Its most prominent constituent with well- known antioxidant, antiinflammatory and anti-cancer properties is thyimoquinone [29]. Thyimoquinone has potential cytoprotective and anti-inflammatory effects; it has been reported that its anti-inflammatory effects are induced by up-regulated expression of heme-oxygenase- 1 and suppression of the cyclooxygenase-2 (COX-2) expression in different cell lines [30]. Thyimoquinone also differentially modulated thyroid hormones and improved thyroid status in rats [31]. Therapeutic effects of Nigella sativa against hypothyroidism is mostly attributed to its antioxidant effects which have been proved in numerous studies [32-34]. It has also been suggested that Nigella sativa protects the hyperplasic changes of thyroid parenchyma in hypothyroid rats [25]. Accordingly, increment in T3 concentrations after treatment with Nigella sativa in the current study, has also been reported in the study by Ismail et al. [35] and the authors concluded that Nigella sativa could raise the lowered serum triiodothyronine concentration without changing the concentration of serum TSH because of its potential ability in repairing the thyroid gland and resynthesizing the thyroid hormone; therefore its therapeutic action could be in part due to antioxidant defense system. Accordingly, reduction of serum anti-TPO concentrations after treatment with Nigella sativa could be explained by its immunomodulatory effects approved previously by its protective roles against several autoimmune disease including type 1 diabetes mellitus and experimental autoimmune encephalomyelitis (EAE) $[36,37]$. The possible underlying mechanisms of immunomodulatory effects of Nigella sativa are reduced synthesis of auto-antibodies, reduced innate and acquired immune cell markers and reduction in transforming growth factor (TGF)- $\beta$ and interleukin (IL)-23 concentrations [36-38].

VEGF is minimally expressed in normal human thyroid cells [39]; however in pathological situations, enhanced TSH concentrations, is a potent stimulator of VEGF secretion [11]. It has been shown that VEGF and one of its receptors, Flt-1, are present in epithelial cells of the thyroid, and VEGF contributes to the regulation of development and function of thyroid epithelial cells [10]. Higher VEGF concentrations are associated with increased risk of recurrence and decreased disease-free survival in papillary thyroid cancer [40]. Strong expression of VEGF has been reported in thyroiditis and thyroid carcinomas [41]; therefore it is a critical cytokine in tumor angiogenesis and will be a potent target of diagnosis and therapy. In the current study, Nigella sativa had a strong impact in reducing VEGF concentrations in Hashimoto's thyroiditis. It is mostly because of antiangiogenic effects of Nigella sativa and its major bioactive compound, thyimoquinone, which has been proven previously in different cancer cell lines [42, 43].
Moreover, in the current study, change in WHR was a significant positive predictor of changes in serum VEGF in Nigella sativa treated group. In fact, VEGF is a multifunctional cytokine and its elevated concentration has been reported previously in several metabolic disorders including type 2 diabetes mellitus and polycystic ovary syndrome. A positive association between serum VEGF and its different genomic variants with the components of metabolic syndrome including central obesity and waist to hip ratio has also been previously reported $[44,45]$. This relationship arise from this fact that adipocytes, specially white adipose tissue cells, produce VEGF which may act as an angiogenic and vascular survival factor for the omental vasculature and has paracrine or systemic endocrine actions, these might hypothetically impact on adipose expansion or the vascular comorbidities of obesity related disease [46]. In this context, it is interesting that Randeva et al. could reported a strong correlation of serum VEGF with waist-to-hip ratio in a considerable cohort of individuals $\left(\chi^{2}=17.42 ; P<0.001\right)$ [47], a measure that, is suggested to be a better marker of subclinical arteriosclerosis and endothelial dysfunction [48] which are common clinical consequences of Hashimoto's thyroiditis $[49,50]$.

Weight reducing effects of Nigella sativa has been observed in previous studies; Zaoui A [51] reported a significant reduction in body weight in rats after 6 weeks treatment with Nigella sativa fixed oil $(P<0.001)$. In other study 3 month supplementation with $1.5 \mathrm{~g}$ per day of powdered Nigella sativa in central obese men significantly reduced body weight [52]. One suggested mechanism is increasing mean rates of satiety and fullness [53]; although, we did not observe any change in dietary energy or nutrient intakes after intervention. Other possible mechanisms are reduced lipid absorption, increased energy expenditure, decreased pre-adipocyte differentiation and proliferation, or decreased lipogenesis and increased lipolysis [54]. The suggested underlying mechanisms of the effects Nigella sativa and its major ingredient thymoquinone's on thyroid health and body weight are summarized in Fig. 2 .

Hashimoto's thyroiditis is more prevalent among females compared with males and women are up to 10 times more likely to develop the disease compared with men [55]. This strong female association remains unexplained although our hunch is that sex steroids have the critical role, as there is compelling evidence for such effects in animal models of many types of autoimmunity [56]. Other possible explanations include skewed X chromosome inactivation and fetal microchimerism [57]. Accordingly, the number of the female participants in the current study was more than men, but the gender distribution among two groups were equal. Therefore, the possible confounding effect of gender could be rule out. Moreover, the comparisons 


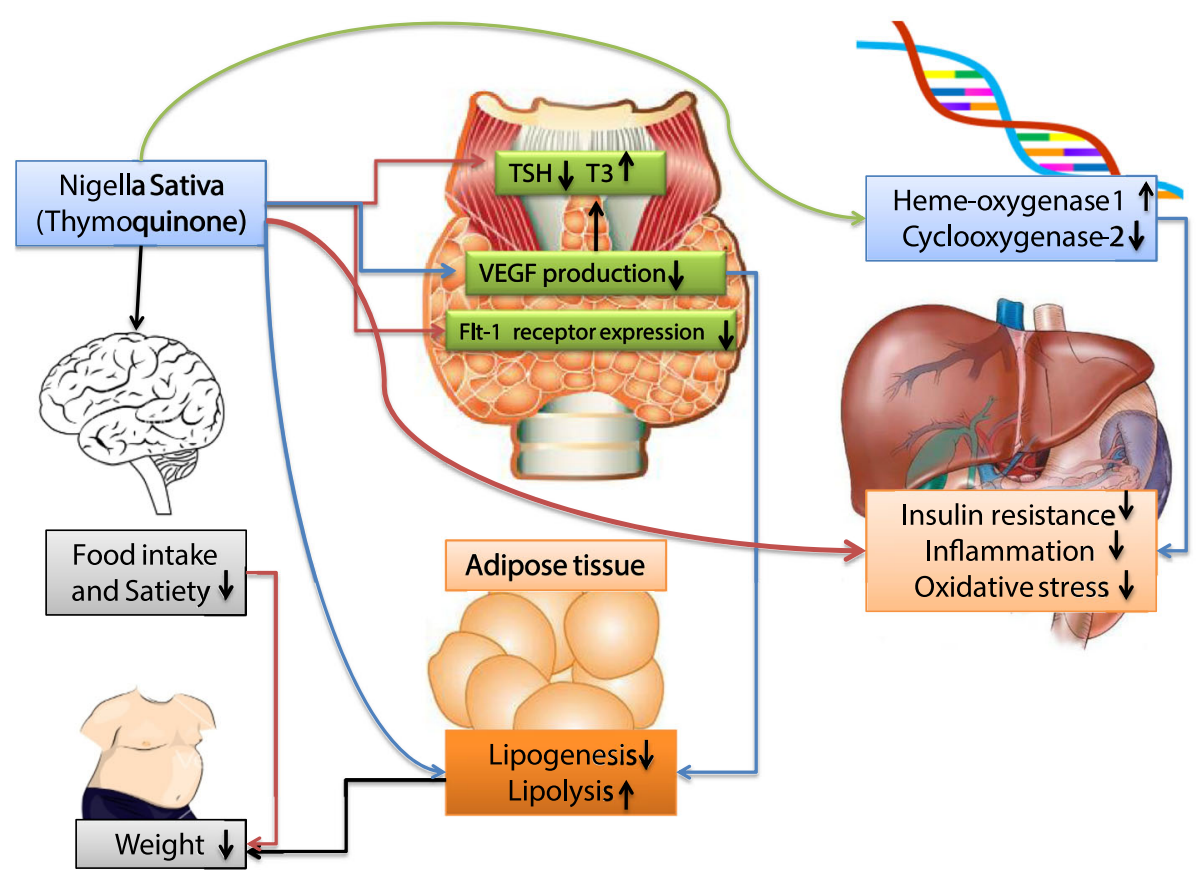

Fig. 2 The probable mechanisms of the effects of Nigella Sativa and its major ingredient Thymoquione on thyroid status and body weight. TSH thyroid stimulating hormone, T3 triiodotyronin, VEGF vascular endotheilial growth factor

between all of the study parameters are adjusted for the possible confounding effects of age, gender and variable's baseline values by ANCOVA.

In the current study serum Nesfatin-1 did not change after Nigella sativa supplementation in Hashimoto's thyroiditis patients. The studies regarding the relationship between serum Nesfatin-1 concentrations and thyroid dysfunction are scarce and conflicting. One study in children demonstrated its reduced concentrations in children with untreated subclinical hypothyroidism [13]; while, other study by Sahin et al. [58] reported no difference in serum Nesfatin-1 concentrations in patients with hypothyroidism compared with healthy control group. Nesfatin-1 is colocalized with TRH and affects the membrane potential of TRH neurons in the paraventricular nucleus, which is known to be closely related to the regulation of thyroid function [15]. However we did not find any change in its concentrations after treatment with Nigella sativa. It could be due to relatively small sample size or treatment duration.

\section{Conclusions}

We have demonstrated beneficial effects of Nigella sativa in improving thyroid status, reducing VEGF and body weight in patients with Hashimoto's thyroiditis. Although no significant change in serum Nesfatin-1 concentrations has been observed, change in anthropometric variables and thyroid hormones were significant predictors of changes in serum Nesfatin-1 concentrations.

\section{Abbreviations}

BMI: Body mass index; HC: Hip circumference; T3: Triiodotyronine; T4: Thyroxine; TG-Ab: Thyroglobulin antibody; TPO-Ab: Thyroid peroxidase antibody; TRH: Thyrotropin releasing hormone; TSH: Thyroid stimulating hormone; VEGF: Vascular endothelial growth factor; WC: Waist circumference; WHR: Waist to hip ratio

\section{Acknowledgement}

The current research was financially supported by a grant from Tabriz University of Medical Sciences.

\section{Funding}

This research has been performed by a grant from Tabriz University of Medical Sciences (Project number: 93173).

\section{Availability of data and materials}

The data are available for any scientific use with kind permission.

\section{Authors' contributions}

MAF conceived and designed the project and wrote the manuscript and performed the statistical analysis, PD was involved in manuscript revision, ST performed the sampling and data collection and MMA was involved in lab works. All authors read and approved the final manuscript.

\section{Competing interests}

The authors declare that they have no competing interests.

\section{Consent for publication}

Not applicable.

\section{Ethics approval and consent to participate}

All participants signed a written informed consent approved by the Institutional Review Board of Tabriz University of Medical Sciences. The study design and protocol was approved by the ethical committee of Tabriz University of Medical Sciences (Project number: 93173). The study has also been registered in Iranian registry of clinical trials (registration number IRCT2015021719082N4- Registered March-15-2015). 


\section{Author details}

N Nutrition Research Center, Department of Community Nutrition, School of Nutrition, Tabriz University of Medical Sciences, Tabriz, Iran. ${ }^{2}$ Student Research Committee, Tabriz University of Medical Sciences, Tabriz, Iran. ${ }^{3}$ Drug Applied Research Center, Tabriz University of Medical Sciences, Tabriz, Iran.

Received: 4 May 2016 Accepted: 2 November 2016

Published online: 16 November 2016

\section{References}

1. Chistiakov DA. Immunogenetics of Hashimoto's thyroiditis. J Autoimmune Dis. 2005;2:1-21

2. Wang C, Crapo LM. The epidemiology of thyroid disease and implications for screening. Endocrinol Metab Clin North Am. 1997;26:189-218.

3. Tunbridge WM, Vanderpump MP. Population screening for autoimmune thyroid disease. Endocrinol Metab Clin North Am. 2000;29:239-53.

4. Vanderpump MP, Tunbridge WM, French JM, Appleton D, Bates D, Clark F et al. The incidence of thyroid disorders in the community: a twenty-year follow-up of the Whickham Survey. Clin Endocrinol (Oxf). 1995;43:55-69.

5. Zaletel K, Gaberscek S. Hashimoto's thyroiditis: from genes to the disease. Curr Genomics. 2011;12(8):576-80

6. Farhangi MA, Eshraghian M, Keshavarz SA, Saboor-Yaraghi AA. Thyroidstimulating hormone, triiodotyronine and thyroxine concentrations and their relationship with metabolic parameters, anthropometric variables and body composition in premenopausal euthyroid obese women. Turk Jem. 2015;19:1-6.

7. Ott RA, McCall AR, McHenry C, Jarosz H, Armin A, Lawrence AM, et al. The incidence of thyroid carcinoma in Hashimoto's thyroiditis. Am Surg. 1987;53(8):442-5

8. Repplinger D, Bargren A, Zhang YW, Adler JT, Haymart M, Chen H. Is Hashimoto's thyroiditis a risk factor for papillary thyroid cancer? J Surg Res. 2008;150(1):49-52.

9. Westermark K, Karlsson FA, Westermark B. Epidermal growth factor modulates thyroid growth and function in culture. Endocrinology. 1983;112(5):1680-6.

10. Wang JF, Milosveski V Schramek C, Fong GH, Becks GP, Hill DJ. Presence and possible role of vascular endothelial growth factor in thyroid cell growth and function. J Endocrinol. 1998;157:5-12.

11. Soh EY, Sobhi SA, Wong M, Meng YG, Siperstein AE, Clark OH, et al. Thyroidstimulating hormone promotes the secretion of vascular endothelial growth factor in thyroid cancer cell lines. Surgery. 1996;120(6):944-7.

12. Ayada C, Toru U, Korkut Y. Nesfatin-1 and its effects on different systems. Hippokratia. 2015;19(1):4-10.

13. Sawicka B, Bossowski A. Analysis of serum levels of nesfatin-1 in children and adolescents with autoimmune thyroid diseases. Pediatr Endocrinol Diabetes Metab. 2012;19(1):5-10.

14. Tohma Y, Akturk M, Altinova A, Yassibas E, Cerit ET, Gulbahar O, et al. Circulating levels of Orexin-A, Nesfatin-1, Agouti-Related peptide, and neuropeptide $Y$ in patients with hyperthyroidism. Thyroid. 2015;2015(25):776-83.

15. Liu F, Yang Q, Gao N, Liu F, Chen S. Decreased plasma Nesfatin-1 level is related to the thyroid dysfunction in patients with type 2 diabetes mellitus. J Diab Res. 2014:1-5. doi:10.1155/2014/128014. Article ID 128014.

16. Yang M, Zhang Z, Wang C, Li K, Li S, Boden G, et al. Nesfatin-1 action in the brain increases insulin sensitivity through Akt/AMPKJTORC2 pathway in dietinduced insulin resistance. Diabetes. 2012;61(8):1959-68.

17. Kohno D, Nakata M, Maejima Y, Shimizu H, Sedbazar U, Yoshida N, et al. Nesfatin-1 neurons in paraventricular and supraoptic nuclei of the rat hypothalamus coexpress oxytocin and vasopressin and are activated by refeeding. Endocrinology. 2008;149(3):1295-301.

18. Monzani F, Di Bello V, Caraccio N, Bertini A, Giorgi D, Giusti C, et al. Effect of levothyroxine on cardiac function and structure in subclinical hypothyroidism: a double blind, placebo-controlled study. J Endocrinol Metab. 2001:86(3):1110-5.

19. Dai DZ, Hu HJ, Yang DM, Hao XM, Zhang GQ, Zhou PA, et al. Chronic levothyroxin treatment is associated with ion channel abnormalities in cardiac and neuronal cells. Clin Exp Pharmacol Physiol. 1999;26(10):819-21.

20. Panebianco P, Rosso D, Destro G, Scarpinato RA, Tropea S, Rizzo A, et al. Use of disphosphonates in the treatment of osteoporosis in thyroidectomized patients on levothyroxin replacement therapy. Arch Gerontol Geriatr. 1997;25(2):219-25.

21. Salem ML. Immunomodulatory and therapeutic properties of the Nigella sativa L. seed. Int Immunopharmacol. 2005;5(13):1749-70.
22. Dollah MA, Parhizkar S, Latiff LA, Hassan MHB. Toxicity effect of Nigella sativa on the liver function of rats. Adv Pharm Bull. 2013;3(1):97-102.

23. Kanter M, Coskun O, Budancamanak M. Hepatoprotective effects of Nigella sativa $L$ and Urtica dioica $L$ on lipid peroxidation, antioxidant enzyme systems and liver enzymes in carbon tetrachloride-treated rats. WJG. 2005; 11(42):6684-8.

24. Abdel-Sater KA. Gastroprotective effects of Nigella Sativa oil on the formation of stress gastritis in hypothyroidal rats. Int J Physiol Pathophysiol Pharmacol. 2009;1 (2):143-9.

25. Khalawi AA, Al-Robai AA, Khoja SM, Shaker AS. Can Nigella Sativa oil (NSO) reverse hypothyroid status induced by PTU in rat? biochemical and histological studies. Life Sci J. 2013;10(2):1-5.

26. Cevikbas HIA, Gurer US, Kiran B, Uresin Y, Rayaman P, et al. Potential adjuvant effects of Nigella Sativa seeds to improve specific immunotherapy in allergic rhinitis patients. Med Princ Pract. 2010:19(3):206-11.

27. Ibrahim RM, Hamdan NS, Mahmud R, Imam MU, Saini SM, Rashid SNA, et al A randomized controlled trial on hypolipidemic effects of Nigella Sativa seeds powder in menopausal women. J Transl Med. 2014;12:82-9.

28. Al-Asoom LI, Al-Shaikh BA, Bamosa AO, El-Bahai MN. Effect of Nigella sativa supplementation to exercise training in a novel model of physiological cardiac hypertrophy. Cardiovasc Toxicol. 2014;14(3):243-50.

29. Omar A, Ghosheh S, Abdulghani A, Houdi A, Crookscor PA. High performance liquid chromatographic analysis of the pharmacologically active quinones and related compounds in the oil of the black seed (Nigella sativa L). J Pharm Biomed Anal. 1999;19:757-62

30. Khader M, Eckl PM. Thymoquinone: an emerging natural drug with a wide range of medical applications. Iran J Basic Med Sci. 2014;17:950-7.

31. Bacak Gullu E, Avci G. Effects of thymoquinone on plasma leptin, insulin, thyroid hormones and lipid profile in rats fed a fatty diet. Kafkas Univ Vet Fak Derg. 2013;19(6):1011-6.

32. Panahi M, Namjoyan F, Shakerin Z. Evaluation of antioxidant effects of Nigella sativa on the ultrastructure of neural tube defects in diabetic rats offspring. Jundishapur J Nat Pharm Prod. 2011;6(1):16-23.

33. Goga A, Hasic S, Becirovic S, Cavar S. Phenolic compounds and antioxidant Activity of extracts of Nigella sativa L. Bull Chemists Technol Bosnia Herzegovina. 2012:39:15-9.

34. Houcher Z, Boudiaf K, Benboubetra M, Houcher B. Effects of methanolic extract and commercial oil of Nigella sativa L. on blood glucose and antioxidant capacity in alloxan-induced diabetic rats. Pteridines. 2007;18(1):8-18.

35. Ismail M, Zabid Y, Hanefi O, Ramazan U. Effect of Nigella sativa L. on serum concentration of thyroid hormone, thyroid stimulating hormone and glucose in alloxan-induced diabetic rabbits. Ir Vet J. 2003:59(9):462-4.

36. Hmza AJA, Osman MT, Adnan A, Omar A. Immunomodulatory effect of Nigella Sativa oil in the disease process of type 1 diabetic rats. Res J Pharm, Bio Chem Sci. 2013:4(1):980-8.

37. Noor NA, Fahmy HM, Mohammed FF, Elsayed AA, Radwan NM. Nigella sativa ameliorates inflammation and demyelination in the experimental autoimmune encephalomyelitis-induced Wistar rats. Int J Clin Exp Pathol. 2015:8(6):6269-86.

38. Tajmiri S, Farhangi MA, Dehghan P. Nigella Sativa treatment and serum concentrations of thyroid hormones, transforming growth factor $\beta$ (TGF- $\beta$ ) and interleukin 23 (IL-23) in patients with Hashimoto's Thyroiditis. Eur J Integ Med. doi: 10.1016/j.eujim.2016.03.003

39. Viglietto G, Maglione D, Rambaldi M. Upregulation of vascular endothelial growth factor (VEGF) and downregulation of placenta growth factor (PIGF) associated with malignancy in human thyroid tumors and cell lines. Oncogene. 1995;11:1569-79.

40. Lennard CM, Patel A, Wilson J, Reinhardt B, Tuman C, Fenton C, et al. Intensity of vascular endothelial growth factor expression is associated with increased risk of recurrence and decreased disease-free survival in papillary thyroid cancer. Surgery. 2001;129(5):552-8.

41. Klein M, Picard E, Vignaud JM, Marie B, Bresler L, Toussaint B, et al. Vascular endothelial growth factor gene and protein: strong expression in thyroiditis and thyroid carcinoma. J Endocrinol. 1999:161(1):41-9.

42. Medenica R, Janssens J, Tarasenko A, Lazovic G, Corbitt W, Powell D, et al. Anti-angiogenic activity of Nigella sativa plant extract in cancer therapy. Proc Annual Meeting Am Assoc Cancer Res. 1997;38:A1377.

43. Iddamaldeniya SS, Thabrew MI, Wickramasinghe SMDN, Ratnatunge N, Thammitiyagodage MG. A long-term investigation of the antihepatocarcinogenic potential of an indigenous medicine comprised of Nigella sativa, Hemidesmus indicus and Smilax glabra. J Carcinog. 2006;5(1):11-7. 
44. Lieb W, Safa R, Benjamin EJ, Xanthakis V, Yin X, Sullivan LM, et al. Vascular endothelial growth factor, its soluble receptor, and hepatocyte growth factor: clinical and genetic correlates and association with vascular function. Eur Heart J. 2009:30:1121-7.

45. Visvikis-Siest S. Association of vascular endothelial growth factor genetic variant with metabolic syndrome. 2014, Google Patents.

46. Mick GJ, Wang X, McCormick K. White adipocyte vascular endothelial growth factor: regulation by insulin. Endocrinology. 2002;143(3):948-53.

47. Randeva HS, Lewandowski KC, Komorowski J, Murray RD, O'Callaghan CJ, et al. Growth hormone replacement decreases plasma levels of matrix metalloproteinases (2 and 9) and vascular endothelial growth factor in growth hormone-deficient individuals. Circulation. 2004;109:2405-10.

48. Villela NR, Aguiar LGK, Bahia L, Bottino D, Bouskela E. Does endothelia dysfunction correlates better with wasit-to-hip ratio than with body mass index or waist circumference among obese patients? Clinics. 2006;61(1):53-8.

49. Ciccone MM, Pergola GD, Porcelli MT, Scicchitano P, Caldarola P, lacoviello $M$, et al. Increased carotid IMT in overweight and obese women affected by Hashimoto's thyroiditis: an adiposity and autoimmune linkage? BMC Cardiovasc Disord. 2010;10:22-30.

50. Atta MN, Elessawy R, Deghedy A, Hafez A, Elsherbiny TM. Hashimoto thyroiditis is an independent cardiovascular risk factor in clinically hypothyroid patients. Alexandria J Med. 2011;47(4):267-76.

51. Zaoui A, Cherrah Y, Alaoui K, Mahassine N, Amarouch H, Hassar M. Effects of Nigella sativa fixed oil on blood homeostasis in rat. J Ethnopharmacol. 2002;79(1):23-6.

52. Datau E, Surachmanto E, Pandelaki K, Langi J. Efficacy of Nigella sativa on serum free testosterone and metabolic disturbances in central obese male. Acta Medica Indonesiana. 2010;42(3):130-4.

53. Qidwai W, Hamza HB, Qureshi R, Gilani A. Effectiveness, safety and tolerability of powdered Nigella sativa [kalonji] seed in capsules on serum lipid levels, blood sugar, blood pressure, and body weight in adults: results of a randomized, double-blind controlled trial. J Altern Complement Med. 2009;15:639-44.

54. Hasani-Ranjbar S, Jouyandeh Z, Abdollahi M. A systematic review of anti-obesity medicinal plants-an update. J Diabetes Metab Disord. 2013;12(1):28-38.

55. Ajjan RA, Weetman AP. The pathogenesis of Hashimoto's thyroiditis: further developments in our understanding. Horm Metab Res. 2015;47(10):702-10.

56. Lee TP, Chiang BL. Sex differences in spontaneous versus induced animal models of autoimmunity. Autoimmun Rev. 2012;11:A422-9.

57. Brix TH, Hansen PS, Kyvik KO, Hegedus L. Aggregation of thyroid autoantibodies in twins from opposite-sex pairs suggests that microchimerism may play a role in the early stages of thyroid autoimmunity. J Clin Endocrinol Metab. 2009;94(11):4439-43.

58. Sahin SB, Ayaz T, Cure MC, Sumer F, llkkilic K. Association of nesfatin-1 levels with fasting and postload glucose levels in patients with hypothyroidism. J Exp Clin Med. 2014;31(4):217-20.

\section{Submit your next manuscript to BioMed Central and we will help you at every step:}

- We accept pre-submission inquiries

- Our selector tool helps you to find the most relevant journal

- We provide round the clock customer support

- Convenient online submission

- Thorough peer review

- Inclusion in PubMed and all major indexing services

- Maximum visibility for your research

Submit your manuscript at www.biomedcentral.com/submit

) Biomed Central 